\title{
ABNORMAL UTERINE BLEEDING IN PERIMENOPAUSE
}

\author{
Shivaji Neelgund ${ }^{1}$, Hiremath P. B ${ }^{2}$ \\ 1 Department of Obstetrics \& Gynaecology, SVMCH \& RC, Ariyur, Pondicherry. \\ 2 Department of Obstetrics \& Gynaecology, SVMCH \& RC, Ariyur, Pondicherry.
}

\section{ABSTRACT}

\section{BACKGROUND}

In the peri-menopausal and post-menopausal women, $70 \%$ of the gynaecological problems are due to AUB. In the United States, $11 \%$ of the hysterectomies are performed for AUB per year. During climacteric, ovarian activity declines leading to anovulation or irregular maturation of follicles. Therefore, the menstrual cycles are often anovulatory and irregular leading to AUB. Prolonged anovulatory periods with unopposed oestrogen stimulation lead to endometrial hyperplasia. This increases the risk of endometrial cancers. Over a decade the progression of endometrial hyperplasia to carcinoma is as follows: Simple hyperplasia - 1\%, Complex hyperplasia - 3\%, Simple hyperplasia with atypia - 8\% and Complex hyperplasia with atypia 29\% [Jeffcoate].

\section{AIMS}

The objective of this study is to correlate the symptoms and the various menstrual patterns to the histopathological diagnosis, so that this knowledge can be applied for an early evaluation and diagnosis of the complications of AUB, and thus arrive at a timely and effective therapeutic strategies.

\section{METHODS}

This is a retrospective study of 314 patients of peri-menopausal age group presenting with AUB in the Department of Gynaecology at SVMCH and RC, Ariyur, Pondicherry, between 2011 and 2014. The study sample consisted of 314 samples of endometrium obtained by dilation and curettage as a day care procedure.

\section{RESULTS}

Menorrhagia is the predominant symptom, 128 cases [40.8\%] and was associated with proliferative, secretory and hyperplastic endometrium. Metrorrhagia cases were 53 [16.9\%], which predominantly showed secretory followed by proliferative histological pattern. There were 4 cases of Endometrial carcinoma [1.27\%]. Simple hyperplasia with atypia were 10 cases [3.29\%] and Complex hyperplasia with atypia cases were 7 [2.33\%].

\section{CONCLUSION}

AUB in perimenopausal period is very significant, as it accounts for about $70 \%$ of all gynaecologic outpatients. Endometrial hyperplasia is a precursor of endometrial carcinoma. Perimenopausal women with heavy or irregular menstrual bleeding should have an endometrial biopsy taken to exclude endometrial disease and early evaluation and diagnosis of the complications of AUB, and thus arrive at timely and effective therapeutic strategies.

\section{KEYWORDS}

Perimenopause, AUB, Hyperplasia, CA Endometrium, D\&C, Histopathology.

HOW TO CITE THIS ARTICLE: Neelgund S, Hiremath PB. Abnormal uterine bleeding in perimenopause. J. Evolution Med. Dent. Sci. 2016;5(51):3337-3341, DOI: 10.14260/jemds/2016/772

\section{INTRODUCTION \\ Throughout the female reproductive life, the uterine endometrium undergoes a complex regular cycle of periodic proliferation, differentiation, breakdown and regeneration. ${ }^{1}$ Almost all women experience menstruation, and it is said to be normal if the uterine bleeding is cyclic from a secretory endometrium associated with an ovulatory cycle, not exceeding a length of five days. Menstrual bleeding is said to be abnormal when the pattern is irregular with a duration of more than 7 days, and amount more than $80 \mathrm{~mL} / \mathrm{menses}$ - menorrhagia.}

Financial or Other, Competing Interest: None.

Submission 05-05-2016, Peer Review 02-06-2016,

Acceptance 09-06-2016, Published 27-06-2016.

Corresponding Author:

Dr. Shivaji Neelgund,

Department of Obstetrics \& Gynaecology,

$S V M C H \& R C$,

Ariyur,

Pondicherry-605102.

E-mail: shivajineelgund5@gmail.com

DOI: $10.14260 /$ jemds $/ 2016 / 772$
Abnormal Uterine Bleeding (AUB) is the term to describe any type of menstrual bleeding that does not fall within the normal ranges for amount, frequency, duration or cyclicity. ${ }^{2}$ Clinically AUB manifests as menorrhagia, polymenorrhoea, polymenorrhagia, metrorrhagia, and menometrorrhagia, intermenstrual bleeding, etc. ${ }^{3}$

A new classification for the causes of abnormal uterine bleeding is based on the acronym PALM-COEIN - Polyps, Adenomyosis, Leiomyoma, Malignancy, Hyperplasia, Coagulopathy, Ovulatory disorders, Endometrial causes, Iatrogenic and Not classified, was developed by the International Federation of Gynaecology and Obstetrics in November 2010. These structural and non-structural aetiologies are for the interpretation of the basic and clinical investigation for a diagnosis and treatment of AUB.

During climacteric, ovarian activity declines leading to anovulation or irregular maturation of follicles. Therefore, the menstrual cycles are often anovulatory and irregular leading to AUB. Prolonged anovulatory periods with unopposed oestrogen stimulation lead to endometrial hyperplasia, thus 
increasing the risk of endometrial cancers. AUB in perimenopausal period is very significant, as it accounts for about $70 \%$ of all gynaecologic outpatients. ${ }^{4}$

Diagnosis and the management strategies of AUB is not complete without histopathological characteristics of endometrial biopsy material. ${ }^{5}$ Endometrial biopsy by a simple procedure of $\mathrm{D}$ and $\mathrm{C}$ [Dilation and curettage] is an effective and safe diagnostic step in evaluation of abnormal uterine bleeding and for the diagnosis of endometrial pathologies such as infections, polyps, endometrial hyperplasia and endometrial carcinoma. ${ }^{6}$ Endometrial curettage is not very expensive as an outpatient procedure; its only disadvantage is it is an invasive procedure. The microscopic appearance of endometrial sampling has many advantages over other diagnostic methods. Hormonal assay are expensive and in rural areas may not be easily available. Ultrasonography evaluates the uterine contour and the status of the ovary. Regarding the endometrium, its reliability is limited to the diagnosis of endometrial atrophy and hyperplasia only. Hysteroscopy and hysterosalpingography are of help in diagnosis of organic pathology. ${ }^{7}$

Histopathological diagnosis varies according to the age; in younger age groups changes in the menstrual pattern due to hormonal effects are more common. Whereas endometrial hyperplasia and endometrial carcinoma are more in the periand post-menopausal group. ${ }^{8}$ Over a decade the progression of hyperplasia to carcinoma is as follows, simple hyperplasia$1 \%$, complex hyperplasia-3\%, simple hyperplasia with atypia$8 \%$ and complex hyperplasia with atypia $29 \%$ [Jeffcoate]. ${ }^{9}$

Irregular bleeding patterns are common during perimenopause, added to it is the increase in the uterine pathology and associated medical complications. AUB with abnormal blood loss has a profound effect on the quality of the woman's life. ${ }^{10}$ In the United States, $11 \%$ of the hysterectomies are performed for AUB per year. ${ }^{11}$

We aimed in this study to assess the frequency of different histopathological findings obtained from endometrial biopsy specimen among perimenopausal women complaining of AUB, to correlate the specific endometrial pathology to different bleeding patterns and clinical feature, so that this knowledge can be applied for an early evaluation and diagnosis of the complications of AUB and thus arrive at timely and effective therapeutic strategies.

\section{METHODS}

This is a retrospective study of 314 patients of perimenopausal age group presenting with AUB in the Department of Gynaecology at SVMCH and RC, Ariyur, Pondicherry, between 2011 and 2014.

All these women had been evaluated by speculum examination to exclude bleeding from cervical lesion and cervical cytology reports were noted.

Only patients, more than 45 years of age with isolated endometrial causes of abnormal uterine bleeding were included for the study. Patients with leiomyoma, cervical, vaginal pathology and patients with systemic or non-pelvic causes of bleeding were excluded from the study.

All the relevant data like age, parity, pattern and duration of abnormal menstrual bleeding, past menstrual history, obstetric history and any other associated gynaecological problems, clinical examination and laboratory investigation results were recorded.
Patients had been screened for hypertension, diabetes mellitus and hypothyroidism.

The study sample consisted of 314 samples of endometrium obtained by dilation and curettage as a day care procedure.

Endometrial curettage samples had been transported in $10 \%$ formalin to the pathology laboratory. The tissue bits were processed in automatic tissue processor and paraffin blocks were prepared and 3-4 microns thick sections were made. Tissue sections were stained with haematoxylin and eosin stain. Microscopic examination was done by pathologists. The Histopathology Diagnosis were recorded.

Histopathological Endometrial patterns were classified as Proliferative Endometrium (PE), Secretory Endometrium (SE), Disordered Proliferative Pattern (DPP), Atrophic Endometrium (AE), Endometrial Polyp (EP), Chronic Endometritis (CE), Endometrial Hyperplasia (EH) and Endometrial Carcinoma (CA). Endometrial hyperplasia was subdivided into Simple hyperplasia with/without atypia and Complex hyperplasia with/without atypia.

\section{RESULTS}

In our study of 314 cases of AUB, almost all histological patterns are seen. The predominant histopathological pattern is Proliferative Endometrium (PE) 96 cases [30.58\%]. The second commonest is Simple Hyperplasia without atypia ( $\mathrm{SH})$ 92 cases [29.30\%]. The various histopathological patterns are represented in Table No. 1 . As seen in the table, the cases of Atrophic endometrium are 16 [5.10\%], Endometrial polyp 12 [3.62\%], Chronic endometritis 11 [3.55\%] and Disordered proliferation endometrium cases were 15 [4.69\%]. There were four cases of Endometrial carcinoma [1.27\%]. Simple hyperplasia with atypia were 10 cases [3.29\%] and Complex hyperplasia with atypia cases were 7 [2.33\%].

Menorrhagia is the predominant symptom, 128 cases [40.8\%] and was associated with proliferative, secretory and hyperplastic endometrium. Metrorrhagia cases were 53 [16.9\%], which predominantly showed secretory followed by proliferative histological pattern, whereas proliferative endometrium was more common in cases of Menometrorrhagia, 45 cases [14.8\%]. Intermenstrual bleeding cases were 28 [8.9\%], which were associated with endometrial polyp and endometritis. Polymenorrhoea and polymenorrhagia cases were 24 [7.6\%] and 36 [11.5\%] respectively. These were associated with hyperplasia, endometrial polyp and secretory endometrium.

The age distribution of AUB is shown in Table No. 3. Maximum number of cases occurred in the age group of $45 \mathrm{yrs}$. to 50 yrs., [68.5\%]. The mean is 46.6 yrs. In our study, the uterus was bulky in 171 cases [54.5\%] and normal size in 143 cases [45.5\%]. Regarding duration of symptoms, 178 cases had the symptoms for period of 3 to 6 months [56.7\%] in 79 cases the duration was 6 months to 1 year [25.2\%] and 57 patients had the symptoms for the period of 3 months [18.5\%].

\begin{tabular}{|c|c|c|}
\hline $\begin{array}{c}\text { Endometrial } \\
\text { Histopathology }\end{array}$ & $\begin{array}{c}\text { No. of } \\
\text { Cases }\end{array}$ & $\mathbf{\%}$ \\
\hline Proliferative Endometrium & 96 & 30.58 \\
\hline Secretory Endometrium & 38 & 12.21 \\
\hline Disordered Proliferation & 15 & 4.69 \\
\hline Atrophic Endometrium & 16 & 5.10 \\
\hline Endometrial Polyp & 12 & 3.62 \\
\hline Endometritis & 11 & 3.55 \\
\hline
\end{tabular}




\begin{tabular}{|c|c|c|}
\hline Simple Hyperplasia without Atypia & 92 & 29.30 \\
\hline Simple Hyperplasia with Atypia & 10 & 3.29 \\
\hline $\begin{array}{c}\text { Complex Hyperplasia without } \\
\text { Atypia }\end{array}$ & 13 & 4.15 \\
\hline Complex Hyperplasia with Atypia & 7 & 2.33 \\
\hline Endometrial Carcinoma & 4 & 1.27 \\
\hline Total & 314 & 100 \\
\hline \multicolumn{3}{|c|}{$\begin{array}{c}\text { Table 1: Distribution of Cases by Endometrial } \\
\text { Histopathology }\end{array}$} \\
\hline
\end{tabular}

\begin{tabular}{|c|c|c|}
\hline Menstrual Patterns & No. of Cases & $\%$ \\
\hline Menorrhagia & 128 & 40.8 \\
\hline Metrorrhagia & 53 & 16.9 \\
\hline Menometrorrhagia & 45 & 14.3 \\
\hline Polymenorrhoea & 24 & 7.6 \\
\hline Polymenorrhagia & 36 & 11.5 \\
\hline Intermenstrual Bleeding & 28 & 8.9 \\
\hline Total & 314 & 100 \\
\hline
\end{tabular}

\begin{tabular}{|c|c|c|c|c|}
\hline Histopathology Diagnosis & No. & $\mathbf{4 5}$ to 50 yrs. & $\mathbf{5 1}$ to 55 yrs. & $\mathbf{> 5 5}$ yrs. \\
\hline Proliferative Endometrium & 96 & 82 & 12 & 2 \\
\hline Secretory Endometrium & 38 & 35 & 3 & 0 \\
\hline Disordered Proliferation & 15 & 13 & 2 & 0 \\
\hline Atrophic Endometrium & 16 & 1 & 6 & 9 \\
\hline Endometrial Polyp & 12 & 8 & 4 & 0 \\
\hline Endometritis & 11 & 6 & 5 & 0 \\
\hline Simple Hyperplasia without Atypia & 92 & 56 & 30 & 6 \\
\hline Simple Hyperplasia with Atypia & 10 & 2 & 5 & 2 \\
\hline Complex Hyperplasia without Atypia & 13 & 7 & 4 & 1 \\
\hline Complex Hyperplasia with Atypia & 7 & 5 & 2 & 2 \\
\hline Endometrial Carcinoma & 4 & 0 & $\mathbf{7 4 = 2 3 . 6 \%}$ & $\mathbf{2 5 = 7 . 9 6 \%}$ \\
\hline Total Table 3: Age Wise Distribution of Histopathology Diagnosis \\
\hline
\end{tabular}

\section{DISCUSSION}

In the peri-menopausal and post-menopausal women, $70 \%$ of the gynaecological problems are due to AUB, as reported by Mahajan et al.12 The cause of abnormal uterine bleeding can be provisionally diagnosed in about 50 to $60 \%$ of the cases by means of detailed history, clinical and pelvic examination, blood tests and ultrasonography - Kotdawala. ${ }^{13} \mathrm{~A}$ definitive diagnosis is very essential for the management of these cases, which can be established only by histopathological examination of the endometrium. Endometrial biopsy by dilation and curettage procedure is very safe and effective in evaluation of the endometrium to derive at a histopathological diagnosis of abnormal endometrial patterns, polyps, endometrial hyperplasia, endometrial carcinoma and infections, as reported by Barut et al. ${ }^{6}$ The accuracy of endometrial biopsy for the detection of endometrial abnormalities has been reported to be as high as $96 \% .^{14}$

Majority of endometrium specimens in our study were of the menstrual phases - PE and SE in 134 cases [42.8\%], same was reported by Spencer and Jetly. ${ }^{15,16}$ Proliferative Endometrium [PE] was dominant, 96 cases [30.6\%] same as reported by Dangla G. ${ }^{17}$ The Secretory endometrium cases were 38 [12.3\%] in our study, whereas Patil et al reported a incidence of $16.11 \% .{ }^{18}$ Sadia Khan reported, proliferative phase was most common histological pattern followed by secretory phase. ${ }^{19}$ The incidence of Disordered Proliferative Endometrium in our study was 15 cases [4.7\%].

Endometrial hyperplasia is a precursor of endometrial carcinoma. Perimenopausal women with heavy or irregular menstrual bleeding should have an endometrial biopsy taken to exclude endometrial disease. ${ }^{20}$ Endometrial hyperplasia was the second commonest histological pattern observed in our study, 122 cases [38.9\%]. Ghani et al has reported a incidence of $41.5 \%$ of endometrial hyperplasia in perimenopausal age group. ${ }^{21}$ Other reports are Dangal G [23\%], Slobada L [22.6\%] and Khare et al [36.2\%].

In the perimenopausal age group, endometrial hyperplasia is due to failure of ovulation leading to exposure of the endometrium to excessive and prolonged estrogenic action produced by the persistent unripe follicles. ${ }^{22}$ The incidence of endometrial hyperplasia without atypia is maximum in the early 50 years' age group and with atypia in early 60 years' age group. 23 The incidence of Simple hyperplasia without atypia in our study is 92 cases [75.4\%] and with atypia is 10 cases [8.2\%]; whereas Complex hyperplasia without atypia were 13 cases [10.7\%] and with atypia were 7 cases [5.7\%]. Simple hyperplasia is the predominant in our study. Doraiswami $\mathrm{S}$ et al reported, $68 \%$ incidence of endometrial hyperplasia in the age group of $40-49$ years. ${ }^{24}$

Studies have reported the incidence of hyperplasia in AUB from $19.4 \%$ to $31.25 \%$ and a few others a higher incidence at $52 \%$ to $62 \%$ range, while the lowest incidence was $7 \%$ as reported by Sanyal. 25

The incidence of Atrophic endometrium in our study is 16 cases [5.10\%]. The cause of bleeding in atrophic endometrium is mostly due to local abnormal defective haemostatic mechanisms or due to anatomic vascular variations. ${ }^{24}$ This incidence varies from $1.1 \%$ to $7 \%$ in other studies. ${ }^{26,27}$

One of the endometrial pathology that can cause AUB with intermenstrual bleeding in women is Endometrial polyps. ${ }^{28}$ Its incidence is about 10 to 24 percent in endometrial biopsy or hysterectomy specimens. ${ }^{29,30}$ Polyps can be missed in curettage specimens. In our study, the incidence of endometrial polyp is 12 cases [3.62\%].

Another cause for AUB is chronic endometritis and its incidence is approximately $8.0 \%{ }^{31}$ In our study, the incidence is 11 cases [3.55\%]. In one-third of these patients, there is no apparent aetiology, but organisms like Chlamydia, Tuberculosis, Neisseria, group B Streptococcus, mycoplasma and many viruses can be responsible for non-specific inflammation of the endometrium. Chronic endometritis manifests as intermenstrual and post-coital bleeding, menorrhagia or amenorrhea with a normal pelvic examination. ${ }^{32}$ To diagnose CE is very important; because with appropriate antimicrobial therapy, the symptoms of these patients improve. 33 
The incidence of Endometrial carcinoma in our study is 4 cases [1.2\%], which is similar to study by Khan $S$ et al and Jairajpuri ZS et al. ${ }^{34}$

The dominant symptom in our study was Menorrhagia 128 cases [40.8\%], which is similar to the reports of Jetley et al and Pillai S.16,35 Although menorrhagia is the most common presentation of AUB, Shapley et al reported a high incidence of resolution of heavy menstrual bleeding during the perimenopausal years, which is important in planning the treatment of these patients. ${ }^{36}$ Jeffcoat has quoted $50 \%$ regression in complex hyperplasia, even in untreated cases, but recommended strict supervision. ${ }^{37}$

In our study, maximum patients attended hospital for treatment after suffering for 3-6 months (56.7\%). In the study of Kathuria R and Bhatnagar B, this incidence is (50\%). ${ }^{38}$

\section{CONCLUSION}

During climacteric, ovarian activity declines leading to anovulation or irregular maturation of follicles. Therefore, the menstrual cycles are often anovulatory and irregular leading to AUB. Prolonged anovulatory periods with unopposed oestrogen stimulation lead to endometrial hyperplasia, thus increasing the risk of endometrial cancers. AUB in perimenopausal period is very significant, as it accounts for about $70 \%$ of all gynaecologic outpatients. Endometrial hyperplasia was the second commonest histological pattern observed in our study. Endometrial hyperplasia is a precursor of endometrial carcinoma. Perimenopausal women with heavy or irregular menstrual bleeding should have an endometrial biopsy taken to exclude endometrial disease and early evaluation and diagnosis of the complications of AUB and thus arrive at timely and effective therapeutic strategies.

\section{REFERENCES}

1. Tavassoli FA, Devilee P. Pathology and genetics of tumours of the breast and female genital organs. Lyon France: IARC. Tumours of the uterine corpus. In: WHO classifications of tumours. 2003:221-32.

2. Munro GM, Critchley HO, Fraser IS, et al. The FIGO classification of causes of abnormal uterine bleeding in the reproductive years. Fertil Steril 2011;95(7):2204-8.

3. Kumar P, Malhotra N. Clinical types of abnormal uterine bleeding. In: Kumar, eds. Jeffcoate's Principle of Gynaecology. $7^{\text {th }}$ ed. New Delhi: Jaypee Brothers Medical Publishers (P) Ltd. 2008:599.

4. Munro GM, Critchley HO, Fraser IS. The FIGO systems for nomenclature and classification of causes of abnormal uterine bleeding in the reproductive years: who needs them? AJOG 2012;207(4):259-65.

5. Samson SL, Donna G. Who needs an endometrial biopsy? Can Fam Physician 2002;48:885-7.

6. Barut A, Barut F, Arikan I, et al. Comparison of the histopathological diagnoses of preoperative dilatation and curettage and hysterectomy specimens. J Obstet Gynaecol Res 2012;38(1):16-22.

7. Gusberg SB, Kaplan AL. Precursors of corpus cancer-4, adenomatous hyperplasia as stage 0 carcinoma of endometrium. American Journal of Obstetrics and Gynaecology 1963;87(5):662-76.

8. Kumar A, Mittal S. Endometrial sampling: How? \& why? Obs and Gynae Today 2007;12(6):284-7.
9. Padubidri VG, Daftary SN. Howkins and bourneshaw's textbook of gynaecology. Perimenopause, menopause, premature menopause and menopausal bleeding: Elsevier, A division of reed Elsevier India Private Limited, Noida 2008:52-62.

10. Speroff L, Fritz MA. Menopause and the perimenopausal transition, clinical endocrinology. In: Speroff L, Fritz MA, eds. Clinical gynaecologic endocrinology and infertility. $7^{\text {th }}$ ed. Philadelphia, London: Lippincott Williams \& Wilkins 2005:628.

11. Farquhar CM, Steiner CA. Hysterectomy rates in the United States 1990-1997. Obstet Gynaecol 2002;99(2):229-34.

12. Mahajan N, Aggarwal M, Bagga A. Health issues of menopausal women in North India. J Midlife Health 2012;3(2):84-7.

13. Kotdawala P, Kotdawala S, Nagar N. Evaluation of endometrium in peri-menopausal abnormal uterine bleeding. J Midlife Health 2013;4(1):16-21.

14. Litta P, Merlin F, Saccardi C, et al. Role of hysteroscopy with endometrial biopsy to rule out endometrial cancer in postmenopausal women with abnormal uterine bleeding. Maturitas 2005;50(2):117-23.

15. Spencer CP, Whitehead MI. Endometrial assessment revisited. Br J Obstet Gynaecol 1999;106:623-32.

16. Jetley S, Rana S, Jairajpuri ZS. Morphological spectrum of endometrial pathology in middle-aged women with atypical uterine bleeding: a study of 219 cases. J Midlife Health 2013;4(4):216-20.

17. Dangal G. A study of endometrium in patients with abnormal uterine bleeding at Chitwan valley. Kathmandu University Medical Journal 2003;1(2):110-2.

18. Patil R, Patil RK, Andola SK, et al. Histopathological spectrum of endometrium in dysfunctional uterine bleeding. Int J Bio Med Res 2013;4(1):2798-801.

19. Khan S, Hameed S, Umber A. Histopathological pattern of endometrium on diagnostic D \& C in patients with abnormal uterine bleeding. Annals 2011;17(2):166-70.

20. Farquhar CM, Lethaby A, Sowter M, et al. An evaluation of risk factors for endometrial hyperplasia in premenopausal women with abnormal menstrual bleeding. Am J Obstet Gynaecol 1999;181(3):525-9.

21. Ghani NA, Abdulrazak AA, Abdullah EM. Abnormal uterine bleeding: a histopathological study. Diyala Journal of Medicine 2013;4(1):56-60.

22. Sloboda L, Molnar E, Popovic Z, et al. Analysis of pathohistological results from the uterine mucosa 196598 at the gynaecology department in Senta. Med Pregl 1999;52(6-8):263-5.

23. Khare A, Bansal R, Sharma S, et al. Morphological spectrum of endometrium in patients presenting with dysfunctional uterine bleeding. People's Journal of scientific research 2012;5(2):13-6.

24. Bhatta S, Sinha AK. Histopathological study of endometrium in abnormal uterine bleeding. $\mathrm{J}$ of Pathology Nepal 2012;2(4):297-300.

25. Doraiswami S, Johnson T, Rao S, et al. Study of endometrial pathology in abnormal uterine bleeding. J of Obstet \& Gynae of India 2011;61(4):426-30. 
26. Sanyal MK, Sanyal S, Bhattacherjee KK, et al. Clinicopathological study of endometrium: a review of three thousand nine hundred twenty cases in different gynaecological abnormalities. J Obstet Gynaecol India 1981;31(5):816-21.

27. Ara S, Roohi M. Abnormal uterine bleeding; histopathological diagnosis by conventional dilatation and curettage. Prof Med J 2011;18:587-91.

28. Mirza T, Akram S, Mirza A, et al. Histopathological pattern of abnormal uterine bleeding in endometrial biopsies. J Basic Applied Sci 2012;8:114-7.

29. Lieng M, Istre O, Qvigstad E. Treatment of endometrial polyps: a systematic review. Acta Obstet Gynaecol Scand 2010;89(8):992-1002.

30. Van Bogaert LJ. Clinicopathologic findings in endometrial polyps. Obstet Gynaecol 1988;71(5):771-3.

31. Epstein E, Ramirez A, Skoog L, et al. Dilatation and curettage fails to detect most focal lesions in the uterine cavity in women with postmenopausal bleeding. Acta Obstet Gynaecol Scand 2001;80(12):1131-6.

32. Mechels TC. Chronic endometritis. Am Fam Physician 1995;52(1):217-22.
33. Vasudeva K, Thrasher TV, Richart RM. Chronic endometritis: a clinical and electron microscopic study. Am J Obstet Gynaecol 1972;112(6):749-58.

34. Eckert LO, Thwin SS, Hillier SL, et al. The antimicrobial treatment of subacute endometritis: a proof of concept study. Am J Obstet Gynaecol 2004;190(2):305-13.

35. Jairajpuri ZS, Rana S, Jetley S. Atypical uterine bleedinghistopathological audit of endometrium-a study of 638 cases. Al Ameen J Med Sci 2013;6(1):21-8.

36. Shobha PS. Sonographic and histopathological correlation and evaluation of endometrium in perimenopausal women with abnormal uterine bleeding. Int J Reprod Contracept Obstet Gynaecol 2014;3(1):113-7.

37. Shapley M, Blagojevic M, Jordan KP, et al. The spontaneous resolution of heavy menstrual bleeding in the perimenopausal years. BJOG 2012;119(5):545-53.

38. Kathuria R, Bhatnagar B. Correlation between D \& C, USG and hysteroscopy findings in diagnosing a cause for abnormal uterine bleeding. Indian Journal of clinical practice 2014;25(5):466-70. 